\title{
REGLAS Y RAZONES SUBYACENTES ${ }^{1}$
}

Hernán Bouvier

CONICET, Argentina

RESUMEN. No es cierto que siempre tras el dictado de una norma existan razones subyacentes. No parece obvio que las normas emanadas de la legislatura posean siempre esa carga de racionalidad que le pretenden atribuir enfoques como el de Frederick Schauer ó el de Manuel Atienza y Juan Ruiz Manero. Su problema está en que han confundido la noción de razón necesaria para interpretar un lenguaje (razón conceptual) con la idea de razón práctica (razón evaluativa). Afirman que los valores sustanciales de tipo moral son precompromisos epistemológicos para comenzar a interpretar el lenguaje jurídico; no obstante que la atribución de razones evaluativas no es ni lógicamente necesaria en el comienzo de una interpretación, ni empíricamente necesaria al final de la investigación lingüística. Esta mala interpretación de nociones fundamentales de la teoría del lenguaje no hace posible describir el derecho tal y como realmente se desarrolla en los procesos de decisión colectiva, además de que juega un rol ideológico en la medida que les atribuye una propiedad de racionalidad de la cual ellos carecen.
ABstract. It is not true that there are always underlying reasons behind the issue of a norm. It is not necessarily clear that norms derived from the legislature always possess the load of rationality which approaches such as those of Frederick Schauer or Manuel Atienza and Juan Ruiz Manero seek to attribute to them. Their problem lies in the fact that they have mistaken the notion of reason necessary to interpret a language (conceptual reason) for the idea of practical reason (evaluative reason). They hold that substantial values of a moral type are epistemological pre-commitments used in order to start interpreting legal language. Nevertheless, the attribution of evaluative reasons is neither logically necessary when beginning an interpretation nor empirically necessary at the end of the linguistic research. This misinterpretation of fundamental notions in the theory of language makes it impossible to describe law as it is really carried out in processes of collective decisions. Moreover, it plays an ideological role in as far as it attributes to them a property of rationality which they lack.

\footnotetext{
${ }^{1}$ El presente trabajo es una versión revisada de "RAZONES, REGLAS E INTERPRETACIÓN. El regreso del legislador racional en el ámbito de la filosofía del derecho” a publicarse en la revista Ideas y Derecho, de la Asociación Argentina de Filosofía del Derecho (Buenos Aires: Rubinzal Culzoni, 2005). Agradezco a la Asociación y en especial al Profesor Ricardo Guibourg por permitirme publicar algunas de las ideas de ese artículo en la presente publicación.
} 


\section{Introducción}

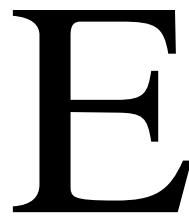

n las discusiones contemporáneas de teoría del derecho resulta un lugar común dar cuenta del derecho y las reglas jurídicas en términos de razones. Un subgrupo de teóricos del derecho considera que la noción de razón, por un lado, otorga una dimensión explicativa sobre el fenómeno práctico del derecho y que, por el otro, esa noción posee primacía conceptual. Se explican las reglas a través de las razones y no a la inversa. Entender las reglas jurídicas en función de las razones que les subyacen (o en función de las razones que aquéllas desplazan) ha sido asumido -en este subgrupo de teóricos- como una categoría central a partir de la cual dar cuenta de diferentes fenómenos centrales del derecho como el de la autoridad o de la interpretación de las normas jurídicas. El alcance y rendimiento de la categoría de razón, sin embargo, no siempre ha sido utilizada de forma consecuente. Es posible sostener que algunos teóricos han extraído conclusiones injustificadas con respecto a la forma en que ella debe utilizarse. La adopción de la idea de razón como central en la empresa teórica ha llevado a suponer que todo derecho y toda regla no puede ser entendida sin la noción de razón. En este sentido, el derecho y las reglas jurídicas serían para todo caso una función de un grupo de razones que o bien hay que presuponer o bien hay que encontrar. Cualquiera sea el caso -se sostiene- no es posible dar cuenta del fenómeno práctico del derecho y de las reglas jurídicas sin la noción de razón. En este trabajo se tratará de mostrar que un subgrupo de quienes sostienen o bien la necesidad de presuponer razones, o bien la necesidad de encontrar razones, han incurrido en un non-sequitur con respecto a los puntos teóricos de partida. Este salto en el razonamiento será llamado aquí non-sequitur interpretativo. Asimismo se sostendrá que ello ha determinado en un sentido importante la revitalización de una antigua presuposición contraria al espíritu del iuspositivismo clásico: la idea del legislador racional. Se tratará de mostrar que quienes han dado este salto injustificado han confundido la noción de razón necesaria para interpretar un lenguaje (que aquí se llamará razón conceptual), con la idea de razón práctica (que aquí se llamará razón evaluativa). Se sostendrá principalmente que esta confusión:

i) proviene de una mala interpretación de nociones fundamentales de la teoría del lenguaje (paradigmáticamente de la doctrina de Donald Davidson)

ii) impide la posibilidad de describir el derecho;

iii) juega un cierto rol ideológico en la medida en que atribuye a los procesos de decisión colectivos (como los de sanción de una ley) una propiedad de racionalidad de la cual ellos carecen o pueden carecer. 
Asimismo se tratará de mostrar que este non-sequitur, originado por la mala interpretación de ciertas teorías del lenguaje, no es atribuible -como creen algunos positivistas- a la noción más refinada del iusnaturalismo actual, encarnada en la figura de John Finnis. Aquí no se tratará de defender la doctrina de Finnis sino de indicar en qué sentido la idea de razón e interpretación puede ser bien o mal entendida, y porqué se considera que el non-sequitur que puede atribuirse a algunos teóricos (paradójicamente iuspositivistas) no es atribuible a autores como Finnis.

Por último se tratará de señalar que la ideología del legislador racional pone en riesgo precisamente la posibilidad de detectar y denunciar el paso de premisas descriptivas a prescriptivas (del ser al deber ser). La subestimación o el olvido de la guillotina de Hume no sólo impide la actividad teórica de quienes (como en el caso de los iuspositivistas exclusivos, o iuspositivistas a secas) consideran como un valor la posibilidad de describir fenómenos sociales, sino también de quienes creen (como en el caso de los filósofos críticos del derecho) que lo importante es contar con herramientas a partir de las cuales detectar cuándo se encubren ciertas prácticas de poder bajo el eufemismo de la racionalidad.

Se sostendrá en definitiva:

i) que el mal empleo de la noción de razón en el terreno del derecho ha reavivado la idea de legislador racional;

ii) que la idea de legislador racional contiene una carga ideológica que pretende esconder la efectiva forma en que se realizan los procesos de decisión colectivas;

iii) que dicha asunción impide utilizar la noción básica de la guillotina de Hume;

iv) que la guillotina de Hume es importante tanto para quien desea limitarse a describir fenómenos sociales sin evaluarlos, como para quien pretende describirlos con el propósito de indicar o poner al descubierto las formas de poder y control social que se esconden tras la retórica jurídica.

\section{La idea de razón subyacente en Frederick Schauer}

Una de las utilizaciones más refinadas de la noción de razón en el terreno del derecho es la presentada por Frederick Schauer². Según este autor, toda

\footnotetext{
${ }^{2}$ F.Schauer, Playing by the Rules. A Philosophical Examination of Rule-Based DecisionMaking in Law and Life (Oxford: Clarendon Press, 1991). Recientemente traducida al español con estudio preliminar de Claudina Orunesu y Jorge L. Rodríguez con el título Las reglas en juego. Un examen filosófico de la toma de decisiones basadas en reglas en el derecho y la vida cotidiana (Madrid: Marcial Pons, 2004).
} 
regla posee un conjunto de razones subyacentes que tarde o temprano (y esto dependerá de qué modelo de decisión se adopte) generará el efecto de sobre e infrainclusión con respecto a las consecuencias elegidas como relevantes por la regla. Así, una regla de tránsito que prohíbe superar los $60 \mathrm{~km}$. por hora y que posee como razón subyacente la protección de la integridad de los transeúntes y ciudadanos en general, será sobreincluyente en el caso de una ambulancia que necesita transportar a un herido imprimiendo a la ambulancia una velocidad mayor a los $60 \mathrm{~km}$., y será infraincluyente en el caso de aquéllos que manejan bajo esa velocidad pero poseen, p.ej., propensión a sufrir ataques epilépticos o desmayos en estaciones de elevada temperatura. La pretensión de la regla (sus razones subyacentes) perseguía, de una forma u otra, evitar accidentes y maximizar la integridad física en el tráfico. Claramente esa justificación subyacente no se satisface ni en el caso de la ambulancia (la regla incluye algo que de acuerdo a la justificación subyacente debería no ser comprendido por ella, de ahí la sobreinclusión), ni en el caso de quien sufre desvanecimientos repentinos (la regla no incluye un caso que de acuerdo a la máxima "maximicemos la seguridad en las calles" debería estar incluído, de ahí la infrainclusión).

Es importante señalar que Schauer concibe a la posibilidad de sobre e infrainclusión como una característica constitutiva, estructural o endémica de un sistema de reglas jurídicas que pretende guiar el comportamiento de otros (sean éstos jueces o ciudadanos).

La posibilidad de evitar la tensión potencial o actual que se suscita entre razones subyacentes y consecuencias previstas por una regla no dependerá, en todo caso, de la existencia o no de razones subyacentes (ya que ellas siempre están presentes) sino de la actitud que se decida adoptar frente a esta tensión. Básicamente puede optarse por: i) un modelo opaco de las reglas con respecto a sus razones subyacentes (modelo atrincherado de las reglas o basado en reglas), ii) un modelo permeable o transparente con respecto a las razones subyacentes (modelo no atrincherado o particularista). Lo que no elimina en ningún caso esta presentación es la existencia para todo caso de dichas razones subyacentes. En todo caso el aplicador puede tomar las reglas como si fueran opacas con respecto a las razones subyacentes. La elección por uno u otro modelo, por tanto, no es impuesto por la ausencia de razones subyacentes (lo cual impondría tomar sólo las reglas y sus consecuencias con independencia de toda otra consideración) sino por la postura o decisión que se tome con respecto a qué modelo sería más conveniente adoptar en un Estado de Derecho ${ }^{3}$. Es decir, dado que se generará una ten-

\footnotetext{
${ }^{3}$ Esto, a su vez, pone la discusión en términos de dos opciones: aquélla que sostiene que hay buenas razones para tener en cuenta las razones subyacentes versus aquélla que sostiene
} 
sión entre tomar un modelo basado en reglas o uno particularista, habrá que sopesar las razones que cada modelo aduce en su favor ${ }^{4}$.

La adopción del primer modelo (atrincherado u opaco con respecto a las razones subyacentes) posee una ventaja y una desventaja:

i) la ventaja consiste en que el legislador elige un preciso estado de cosas (no viajar a más de $60 \mathrm{~km}$. por hora) que concuerda (pero no se superpone completamente) con las razones subyacentes, e impide que se reabra (al nivel de aplicación del derecho) el balance de razones sobre los estados de cosas que maximizarían la satisfacción de las razones subyacentes. En este sentido, se clausura la posibilidad de decisión discrecional del juez y se impide que un órgano no elegido democráticamente decida sobre cuestiones privativas del Poder Legislativo ${ }^{5}$. Las ventajas políticas, en este sentido, consisten en que, en primer lugar, se evita la delegación de poder legislativo clausurando la reapertura del balance de razones por parte del juez; en segundo lugar, se refuerza el ideal de certeza o seguridad jurídica. Mediante reglas claras y precisas se favorece que el ciudadano conozca de antemano en forma exhaustiva cuál es el estado de cosas que debería evitar o al cual debe ajustar su conducta.

ii) la desventaja consiste precisamente en el fenómeno de la sobre e infrainclusión. Siempre podrán suscitarse casos extravagantes en que resulte costoso adoptar un sistema de reglas atrincherado. En el caso de la sobreinclusión porque se estima que existe un estado de cosas

que hay buenas razones para basarse en un modelo de reglas. Esta distinción da lugar en Schauer a dos tipos de justificaciones o razones en favor de los modelos: la justificación sustantiva y la justificación para generación de reglas. Según la definición del propio autor:

"[la] justificación sustantiva determina las razones que sustentan u objetivos que subyacen a la regla... [la] justificación para la generación de reglas, suministra el fundamento para especificar la justificación sustantiva en forma de regla” F.Schauer, ob. Cit. p. 94 de la versión inglesa, p. 154 de la versión española.

${ }^{4}$ El mismo problema o tensión entre estos dos modelos puede analizarse en términos de los costes de la taxatividad, esto es, de un modelo basado en reglas. Al respecto puede verse el análisis exhaustivo del problema que lleva adelante Víctor Ferreres Comella con copiosa referencia de la jurisprudencia del Tribunal Supremo, el Tribunal Constitucional, el Tribunal Europeo de Derechos Humanos y la Corte Suprema de EEUU, en El principio de taxatividad en materia penal y el valor normativo de la jurisprudencia (Madrid: Civitas, 2002).

${ }^{5}$ Esta es paradigmáticamente una de las formas en que puede discutirse en el terreno de la Filosofía Política y el Derecho Constitucional el problema del argumento contramayoritario o del activismo judicial. Es decir, la posibilidad y conveniencia de que los jueces tomen para sí potestades que deberían estar en manos de órganos democráticos. Cfr. Gargarella, Roberto. “Los jueces frente al `coto vedado’». Revista Discusiones. Número 1. Ed. de la Universidad Nacional del Sur. 2000. pp. 53-65. En lo que concierne a la relevancia de la discusión en el ámbito constitucional puede verse Ferreres Comella, Víctor. "Una defensa de la rigidez constitucional”. Revista Doxa 23. Universidad de Alicante. 2000. pp 29-49. 
que debería ser excluido del alcance de la norma; en el caso de la infrainclusión porque se estima que algo que no cae bajo el alcance de la norma debería (de acuerdo a sus razones subyacentes) estar incluido en ella. La desventaja precisamente consiste en que existen estados de cosas que se querría favorecer o desalentar pero que, dada la técnica de atrincheramiento y opacidad, son regulados de forma subóptima ${ }^{6}$.

Por el contrario, el segundo modelo (no atrincherado o no focalizado en decisiones en base a reglas) puede considerar que la satisfacción de las razones subyacentes es un valor supremo por lo cual se justifica adoptar fórmulas legislativas que en vez de precisar un estado de cosas de forma exhaustiva, se limite a expresar más o menos claramente las razones o valores que se quiere favorecer. Así, por ejemplo, se puede optar por cambiar la técnica legislativa, abandonando el modelo de las reglas y formulando un principio que (en nuestro ejemplo) tendría el siguiente contenido "debe sancionarse los actos que pongan en peligro o efectivamente dañen a transeúntes y automovilistas en el tráfico” o "debe maximizarse la seguridad en el tráfico”. La adopción del segundo modelo también posee un grupo claro de ventajas y un grupo claro de desventajas:

i) como ventaja, elimina el efecto de sobre e infrainclusión toda vez que una fórmula con una amplitud tal está en condiciones de lidiar o solucionar correctamente los casos extravagantes, incluyendo casos como el de las personas con problemas de salud que no deberían conducir (que en el modelo anterior quedaban fuera del alcance de la regla) y excluyendo casos como el de la ambulancia (que en el modelo anterior eran alcanzados por la regla).

ii) como desventaja surge precisamente la negación de las dos ventajas del modelo anterior. En primer lugar se delega a un órgano no-legislativo la posibilidad de decidir cuál sería el estado de cosas que corresponde a una fórmula amplia como "maximizar la seguridad en el tráfico”. En segundo lugar se compromete seriamente la seguridad jurídica o certeza ya que no es posible conocer ex-ante y de forma precisa cuáles serían los estados de cosas que el ciudadano debería perseguir o evitar. Por último, y como consecuencia de lo anterior, se compromete seriamente la autonomía individual de las personas ya

\footnotetext{
${ }^{6}$ Sobre el carácter subóptimo de las reglas, Cfr. F. Schauer, ob. Cit. pp. 100-101 versión inglesa y 160-161 versión española.
} 
que no se les informa previamente de las reglas y condiciones a partir de las cuales podrían diseñar un cierto plan de vida ${ }^{7}$.

Esquemáticamente podría compararse ambos modelos mediante un cuadro en donde los signos positivos (+) aparecen simbolizando las ventajas y los negativos $(-)$ las desventajas.

Así:

\begin{tabular}{|l|c|c|}
\hline & $\begin{array}{c}\text { Modelo opaco o } \\
\text { atrincherado } \\
\text { (basado en reglas) }\end{array}$ & $\begin{array}{c}\text { Modelo no atrincherado o } \\
\text { transparente } \\
\text { (basado en principios) }\end{array}$ \\
\hline $\begin{array}{l}\text { Satisfacción de las } \\
\text { razones subyacentes }\end{array}$ & - & + \\
\hline $\begin{array}{l}\text { No delegación de poder } \\
\text { legislativo a los jueces }\end{array}$ & + & - \\
\hline $\begin{array}{l}\text { Certeza o seguridad } \\
\text { jurídica }\end{array}$ & + & - \\
\hline
\end{tabular}

Como se ha dicho previamente, esta presentación de las opciones entre dos modelos pretende retratar una cierta tensión y dilema frente al cual se debe decidir: si el modelo que protege y favorece las razones subyacentes elegidas por el legislador, que otorga poder a los jueces y que pone en riesgo la seguridad jurídica; o aquél que no siempre satisface la justificación subyacente, no delega poder a los órganos de aplicación y favorece la certeza o principio de legalidad en sentido amplio. Basta aquí decir que la obra de Schauer está dirigida a apuntalar una defensa del modelo basado en reglas opacas a sus razones subyacentes. No obstante, no es este el punto donde querría detenerme sino más bien en los elementos a partir de los cuales Schauer realiza este tipo de análisis y el tipo de entidades que el autor presupone existentes en todo análisis del derecho.

Puede decirse que la ontología de Schauer presupone al menos tres tipos de entes o elementos en el ámbito del derecho:

i) razones subyacentes o propósitos perseguidos por el legislador;

ii) reglas opacas a estas razones o propósitos;

iii) principios o normas no opacas a las razones;

Es fácil ver que el modelo de Schauer sostiene que para todo caso las reglas poseen un propósito o razón subyacente que podrá ser o no tomado en cuenta de acuerdo al modelo que se decida adoptar. En ningún caso se prevé la posibilidad de reglas dictadas irracionalmente, a ciegas, sin conocimiento

\footnotetext{
${ }^{7}$ Es decir, no se provee de reglas claras, prospectivas, públicas e irretroactivas. Sobre la relación entre certeza, autonomía y plan de vida puede consultarse, en el marco de esta discusión a Bayón, Juan Carlos. "Principios y reglas: legislación y juridiscción en el Estado Constitucional” en Jueces para la Democracia, n²7, noviembre, 1996. pp. 41-49.
} 
de propósitos, o sin la previsión de ciertos fines u objetivos a proteger o alcanzar. Se excluye, en definitiva, reglas sin razones subyacentes. Este puede considerarse el primer paso hacia la revitalización de la idea del legislador racional. Toda norma, cualquiera sea el caso, tendrá una razón subyacente la cual, por motivos políticos, morales o prudenciales podemos elegir dejar de lado mediante la adopción de un modelo de reglas atrincherado y opaco. No se sostiene que existen casos en que hay reglas que no tienen razones o que han sido emanadas sin la más mínima consideración de qué estado de cosas se querría favorecer. Se sostiene, en cambio, que siempre existen estas consideraciones las cuales podemos o no tomar como relevantes a la hora de decidir un caso y ello dependerá de los valores (certeza, autonomía, división de poderes, etc.) que se pretenda proteger. Se aduce, en definitiva, que no hay reglas sin razones. Más adelante se regresará sobre este argumento tratando de mostrar cómo ello contribuye a una tergiversación (idealización) de la forma en que realmente son tomados los procesos de decisión colectiva y cómo un análisis tal impide dar cuenta o describir los casos (bastante usuales) en que el legislador obra por error, desinterés o desconocimiento del tipo de intereses o valores que está favoreciendo. Excluye, en definitiva, distinguir entre lo que llamaríamos un buen legislador (reflexivo, abierto a la discusión y al balance de razones) y un mal legislador (aquél que no tiene en cuenta el conjunto de valores que se están en juego al momento de legislar) ${ }^{8}$. Previo analizar más detalladamente los posibles orígenes de esta posición por parte de Schauer, se analizará un discurso teórico que se encuentra en la misma línea de Schauer y que intenta extraer de esta teoría consecuencias concretas para la interpretación de determinadas instituciones jurídicas como el abuso del derecho y el fraude a la ley. Me refiero al análisis que llevan adelante Manuel Atienza y Juan Ruiz Manero en Ilícitos atípicos $^{9}$ (de ahora en adelante $I A$ ).

\footnotetext{
${ }^{8}$ Como se verá, el análisis à la Schauer impide hacer uso, en primer lugar, de la conocida máxima según la cual una cosa es el derecho otra su mérito o demérito (que para el caso debería transformarse en una cosa son las reglas o leyes otra es si efectivamente son el producto de una decisión racional o que tiene en cuenta razones); en segundo lugar impide tomar en cuenta los casos en que el legislador es completamente inconsciente del tipo de valores (suponiendo que existan) o ideología que está favoreciendo, lo que constituye un elemento de análisis central para quienes creen que es posible que los funcionarios (y cualquier ciudadano en general) actúe como vehículo inconsciente de poder (Foucault). Es decir, actuando los intereses ajenos y fortaleciendo ciertas estructuras de poder sin notarlo.
}

${ }^{9}$ Atienza, M. y Ruiz Manero, J. Ilícitos atípicos (Madrid: Editorial Trotta, 2000). 


\section{Reglas y principios en Atienza y Ruiz Manero}

Tomando la estructura de Schauer previamente descripta los autores distinguen claramente entre dos tipos de normas: las reglas y los principios. Las reglas, a su vez, son subdivididas en dos tipos: las reglas de acción y las de fin. Las reglas de acción son pautas específicas de conducta que establecen mandatos o permisiones y detentan la siguiente estructura: un antecedente o condición de aplicación, que contiene un conjunto cerrado de propiedades (en el ejemplo de más arriba “velocidad máxima de 60 km por hora”), y un consecuente o solución normativa con dos elementos, una acción o clase de acciones y su calificación deóntica (v.g. “obligatorio sancionar con multa de 200 a 1000 pesos”) ${ }^{10}$. Las reglas de fin, por su parte, preven como solución o consecuencia normativa no la realización de una acción (castigar, sancionar, etc.) sino la consecución de un cierto estado de cosas ${ }^{11}$. Para nuestro análisis bastará concentrarse en el primer tipo de reglas.

Por su parte los principios son definidos, por oposición a las reglas, como normas que tienen por rasgo característico

“...que su antecedente o condición de aplicación no se contiene otra cosa sino la propiedad de que haya una oportunidad de realizar la conducta prescripta en el consecuente; y en este último se contiene una prohibición, un deber o permisión prima facie de realizar una cierta acción (en el caso de los principios en sentido estricto) o de dar lugar a un cierto estado de cosas en la mayor medida posible (en el caso de las directrices o normas programáticas)...[...]...De esta forma, los principios - a diferencia de las reglas- no pretenden excluir la deliberación del destinatario como base de la determinación de la conducta a seguir sino que, bien al contrario, exigen tal deliberación...”12

Para estos autores, la diferencia central entre reglas y principios radica precisamente en que en el antecedente de la regla figuran condiciones cerradas, mientras en los principios figuran condiciones abiertas de aplicación las cuales fuerzan (o estimulan) la deliberación sobre el estado de cosas que se correspondería con el propósito del principio. Como segunda diferencia, mientras que las reglas estipulan la acción que se sigue como consecuencia de la verificación de las condiciones de aplicación (v.g. la consecuencia de sancionar, castigar, etc.) los principios estipulan consecuencias que tienen el peso o valor de deberes o calificaciones deónticas prima facie, es decir

\footnotetext{
${ }^{10}$ Esta forma de presentar las reglas como compuestos de condiciones de aplicación y soluciones puede encontrarse (de forma mucho más sofisticada) en la presentación de las normas que hacen Alchourrón y Bulygin como compuestos de casos genéricos y soluciones normativas. Cfr. Alchourrón, C. y Bulygin, E. Introducción a la metodología de las ciencias sociales y jurídicas (Buenos Aires: Astrea, 1975) p. 79. Sobre la noción de caso genérico ibídem. p. 59.

${ }^{11}$ Atienza M., Ruiz Manero, J., IA, ob. cit. pp. 16 y 17.

${ }^{12}$ Atienza M., Ruiz Manero, J., IA, ob. cit. pp. 18 y 19.
} 
que se aplican en ausencia de otros principios que derroten al principio en cuestión ${ }^{13}$. Por otra parte, y en lo que a nuestra discusión interesa, los autores distinguen (como se ha visto en el párrafo citado) entre principios en sentido estricto y principios como directrices o normas programáticas. Los principios en sentido estricto tienen como función fundamental la de brindar la justificación subyacente a las reglas. Así la regla de velocidad máxima en el tráfico posee un principio en sentido estricto que le otorga justificación, según el cual "es valioso maximizar la seguridad en el tráfico" o, si se quiere "se debe minimizar las situaciones de peligro o daño a terceros". Para los autores, la función primordial de los principios es otorgar la justificación subyacente a las reglas, lo cual los acerca todavía más a la posición de Schauer en el sentido que afirman lisa y llanamente que las reglas poseen este aspecto subyacente del cual podremos luego (si nos parece importante) desembarazarnos tomando en cuenta sólo el estado de cosas atrincherado por la regla, desechando su base justificativa. Es esta concepción de las reglas la que les permite a los autores distinguir entre el elemento propiamente directivo de las normas y el aspecto justificativo. En sus palabras:

“...[habría] que distinguir entre el elemento propiamente directivo de las normas: su función de dirigir la conducta, y el elemento justificativo: lo que hace que la conducta prohibida aparezca como disvaliosa, la obligatoria como valiosa, y la permitida como indiferente. Hay pues, una relación intrínseca entre las normas y los valores, puesto que el establecer, por ejemplo, la obligatoriedad de una acción p implica necesariamente atribuir a esa acción un valor positivo...."14 (el subrayado es mío).

Aquello a lo que los autores refieren con la expresión "lo que hace que la conducta aparezca como disvaliosa, valiosa, o indiferente" es precisamente la idea de valor, razón o justificación subyacente. Es decir, aquéllo que subyace a toda directiva y que les permitirá decir luego, siguiendo a Schauer, que todas las reglas presentarán este defecto endémico o estruc-

${ }^{13}$ La diferencia entre deberes absolutos y prima facie tiene origen en una distinción proveniente de la Filosofía Moral y atribuida a David Ross (aunque tributaria en realidad de las ideas de Prichard). Cfr. Ross, David. Lo correcto y lo bueno. (México: Ed. Sígueme, 2001). Trad. de Leonardo Rodríguez Duplá. La terminología ha sido adoptada también en el terreno del derecho con el propósito de dar cuenta de la distinción propuesta por Ronald Dworkin entre principios y reglas. Según Dworkin las reglas poseen una dimensión todo o nada (agotan el espacio lógico de aplicación) mientras los principios poseen una dimensión de peso que permite la relación de conflicto y superación entre ellos (derrotabilidad). También se ha pretendido hablar o reconstruir las reglas en términos de deberes prima facie y derrotabilidad. La literatura en ese sentido está comenzando a tornarse inabarcable. Al respecto puede verse, como mínimo, Alchourrón, Carlos E. "Para una lógica de las razones prima facie”, Análisis Filosófico XVI (2) (1996), pp. 113-124. Resume con precisión el estado de la cuestión Bayón, Juan Carlos, “¿Por qué es derrotable el razonamiento jurídico?”, Doxa, 24, 2001, pp. 35-62.

${ }^{14} I A$, ob. cit., pp. 20-21. 
tural de la sobre e infrainclusión con respecto a las razones que motivaron su promulgación. Este compromiso teórico lleva a los autores a terminar asumiendo que:

"no se puede descartar la posibilidad de que en un determinado supuesto, lo que ordena (o permite) la regla difiera de lo ordenado o permitido por su justificación subyacente (el principio o principios de los cuales la regla es una especificación)"15

Parece seguirse claramente de lo transcripto, y en especial de la parte resaltada, que los autores están dispuestos, al igual que Schauer, a partir del supuesto que toda norma posee al menos un principio que le subyace o una razón que la justifica. Asumen, por tanto, que toda regla posee una razón, y que ella puede expresar un juicio de desaprobación (si es prohibitiva), de aprobación (si es obligatoria) o de indiferencia (si es permitida). Lo que no se ve hasta el momento es porqué si estamos comprometidos con la descripción de las normas emanadas del poder legislativo, tenemos que comprometernos con asumir que toda norma que expresa una obligación posee una razón subyacente o una base justificativa que el legislador ha tenido en cuenta al momento de emanar la norma. Parece perfectamente imaginable la situación de un Poder Legislativo que sancione leyes continuamente sin entender qué es lo que está sancionando, sin tener en cuenta las razones que favorece, o sin pensar en razón o estado de cosas alguno al cual favorecer o proteger. Parece totalmente posible contar con legisladores (malos legisladores, debe decirse) que sancionen leyes sin ningún mérito, razón o justificación. Una vez más, los actos de la legislatura son una cosa (y es eso a lo que debería limitarse a describir un teórico del derecho) sus méritos o deméritos, otra ${ }^{16}$. En la próxima sección se analizará la relevancia de la noción de razón en el ámbito de la interpretación del lenguaje, tratando de mostrar que el tipo de razones que son necesarias para interpretar el lenguaje de un tercero no tienen porqué suponer el tipo de razones en las que están pensando Schauer y Atienza-Ruiz Manero.

${ }^{15}$ IA, ob. cit., p. 23.

${ }^{16}$ Los autores pueden estar pensando, en cambio, en la idea de regla como razón que es tributaria del pensamiento de Hart, y más precisamente de la noción de regla del segundo Wittgenstein. Pero si ese fuera el caso (y sobre ello se regresará más adelante) la tergiversación es doble. Porque ni Hart ni Wittgenstein creen que tras la regla subsisten razones, sino más bien que la regla es una razón para quien la sigue, i.e. que ve un motivo para seguirla, y está dispuesto a partir de ella a formular un juicio de reproche ante el desvío o desobediencia. Este concepto de regla no incluye algo subyacente (algo en virtud de lo cual una cosa deviene o se presenta como otra; v.g. una regla como función de sus razones subyacentes) sino la noción de identidad según el cual tener una regla es tener una disposición a seguirla y a criticar su desobediencia. La noción Wittgensteiniana-Hartiana de regla no necesita algo subyacente: una regla es una razón. 


\title{
IV. El origen de la confusión. La necesidad de atribuir razones en la situación de interpretación
}

\author{
IV.a. Razones conceptuales y razones evaluativas en la interpretación \\ (Davidson). El non-sequitur interpretativo
}

Luego del giro "postpositivista” de la filosofía anglosajona en los años cincuenta del siglo pasado se ha asumido -como respuesta a los desafíos escépticos- que la noción de interpretación y traducción de un lenguaje está íntimamente ligada con la necesidad conceptual de atribuir razones en el hablante o sujeto a ser interpretado ${ }^{17}$. En especial se considera que no es posible intentar interpretar un lenguaje (jurídico, o práctico en general) si no se parte de ciertos supuestos o atribuciones en las intenciones del hablante. Según este modo de ver las cosas, sería una empresa imposible tratar de averiguar el contenido semántico de un lenguaje sin partir de la base que la persona interpretada asume, al menos, algunos de los presupuestos que el intérprete tiene en cuenta para construir su manual de traducción (para el caso, un texto de dogmática, o cualquier obra de doctrina que intente descifrar qué quiso decir el legislador). Se sostiene que, si se partiera de la base que el hablante no cumple con ciertas condiciones mínimas del lenguaje, la actividad de interpretar constituiría un sinsentido y la caída en el escepticismo, inevitable. Es en este contexto que se enmarca, fundamentalmente, la obra de Donald Davidson y en especial dos de sus artículos que intentan, por un lado, salir del escepticismo y, por el otro, dar cuenta de los compromisos teóricos mínimos que se deben asumir a la hora de interpretar el lenguaje de un tercero $^{18}$.

\footnotetext{
${ }^{17}$ Sobre el impacto del postpositivismo en el terreno del derecho: Patterson, Dennis, "Postmodernism”, en Dennis Patterson (ed.), A Companion to Philosophy of Law and Legal Theory (Cambridge, Massachusetts: Blackwell, 1996). Sobre ese giro en el ámbito exclusivamente filosófico (con un análisis de la obra del segundo Wittgenstein y sus conexiones con Quine): Hacker, P.M.S., Wittgenstein's Place in Twentieth-Century Analytic Philosophy (Oxford: Blackwell Publishers, 1996), pp. 103-110, en donde se analiza puntualmente lo que el mismo autor llama el repudio del análisis.

${ }^{18}$ Me refiero a Davidson, D. “On the Very Idea of a Conceptual Scheme” (de ahora en adelante OVICS) en, Id. Inquiries into Truth and Interpretation (Oxford: Clarendon Press, 1984) pp. 183-198 y “A Coherence Theory of Truth and Knowledge” (de ahora en adelante CTTK) en Id. Truth and Interpretation. Perspectives on the Philosophy of Donald Davidson. Ernest LePore (ed.) (Oxford: Blackwell, 1986) pp. 307-319. En realidad la teoría de Davidson enlaza estrechamente la teoría de la acción con la del lenguaje e interpretación. Los puntos básicos de la teoría de la acción en Davidson (con repercusión en OVICS y CTTK) se encuentran en id. Actions, Reasons and Causes en White, A. (ed.) Philosophy of Action (Oxford: Oxford University Press, 1969).
} 
Retomando la noción del principio de Caridad utilizada por Quine (que a su vez éste toma de Wilson ${ }^{19}$ ), Davidson sostiene que se deben asumir ciertos presupuestos conceptuales o lógicos en el hablante interpretado. En especial, el principio de caridad incluye la atribución en el hablante de ciertas categorías que aquí se llamarán conceptuales. De acuerdo a ellas, debemos suponer que el hablante utiliza el principio de no contradicción y tercero excluído como lo hacemos nosotros, y que la información que da sobre el mundo es verídica (es decir, no padece de alucinaciones ni pretende, en general, engañarnos sobre las cosas a las cuales refiere o sobre las cosas en presencia de las cuales emite un sonido, señala, nombra o juzga). Por último, debemos interpretar el lenguaje de forma teleológica o intencional, es decir, en términos de qué quiso hacer la persona que se pretende interpretar. Aquí surgen dos posibilidades: o atribuimos al hablante la intención o actitud proposicional de describir el mundo (i.e. la expresión de una creencia) o atribuimos al hablante la intención o actitud proposicional de que cierto estado del mundo cambie en determinado aspecto (i.e. la expresión de un deseo). Así, si el hablante expresa que no desea que los automóviles circulen a más de $60 \mathrm{~km}$. por hora debemos presuponer al menos (y esto luego puede ser refutado dependiendo de otras pruebas empíricas) que cuando dijo automóvil no se refería vehículos tracción a sangre (principio de identidad), que no está de acuerdo al mismo tiempo con que se circule y no se circule a más de 60 km. (principio de no contradicción), que no ha intentado engañarnos, y que desea que el mundo cambie en ese aspecto. Es decir, que su expresión o acción se explica por su voluntad de que los vehículos no alcancen esa velocidad, y no por, p.ej. por otra creencia mítica o irrazonable. Presuponemos que el individuo considera indeseable esa velocidad.

Puede verse hasta aquí qué rol juega en la situación de interpretación la atribución o presuposición de estos esquemas o categorías en el hablante (principio de no contradicción, identidad, veracidad, etc.). Si no pudiésemos partir de estos presupuestos, si no pudiésemos partir del presupuesto que el hablante identifica mínimamente el mundo como lo hace el intérprete y tampoco pudiésemos atribuir a sus deseos una cierta explicación en términos de lo que el sujeto quería y no quería que sucediese, sería imposible embarcarse en cualquier actividad teórica de interpretación ${ }^{20}$. Digamos que es necesario

\footnotetext{
${ }^{19}$ Cfr. Sanchez Durá y Vidarte, V.S. “Interpretación: radical y cultural” en Dascal, M. (ed.) Filosofía del Lenguaje II. Pragmática. Enciclopedia Iberoamericana de Filosofía. (Madrid: Trotta, 1999), p. 172.

${ }^{20}$ Para Davidson constituye una especie de contradicción (teórica) en los términos sostener que existe un lenguaje pero no es traducible: “...nada puede contar como evidencia de que cierta actividad o práctica no puede ser interpretada en nuestro lenguaje sin implicar, al mismo tiempo, una prueba de que en realidad ese lenguaje no es una instancia de comportamiento
} 
atribuir al hablante (o conjunto de hablantes) un mínimum de racionalidad sin el cual no puede comenzarse la traducción. Llamemos a este conjunto de precompromisos conceptuales razones conceptuales o lógicas. Como puede verse, ellas constituyen una serie de presupuestos epistemológicos a partir de los cuales elucidar qué significan (qué contenido tienen) las palabras o textos de otros ${ }^{21}$. Estas razones o presupuestos conceptuales, a su vez, pueden utilizarse sólo bajo ciertas restricciones. En especial las restricciones se refieren a qué o cuánto es admisible atribuir o presuponer en el hablante a la hora de interpretarlo. Si simplemente se presupusiera en el hablante todas nuestras categorías, creencias y convicciones, la línea entre descripción e invención (tergiversación de datos) desaparecería. Todo lo que al teórico le parece que debería pensar o creer el hablante se transformaría en todo lo que el hablante piensa o cree. No habría, en definitiva, distinción entre creencias y mundo, entre hipótesis y realidad. En palabras de Acero, Bustos y Quesada:

"el intérprete ha de imputar al hablante aquellas creencias e intenciones que optimizan el mutuo acuerdo sobre cuál sea la causa racional de la proferencia. Es decir, el Principio de Caridad le pide al intérprete que atribuya al hablante las creencias e intenciones que constituirían para el primero una racionalización de la proferencia. Obviamente este principio es válido dentro de ciertos límites, y la primera restricción a que ha de someterse es la que no nos lleve a pensar que el hablante tiene deseos y/o creencias explícitamente contradictorios, y que lo sabe. Si se alcanzase una conclusión así, habría que admitir que el intérprete había cometido algún error en sus asignaciones previas, y sería forzoso proceder a su localización. Por otro lado, este principio tampoco nos abre las puertas a atribuir al hablante cualesquiera creencias y deseos, y por consiguiente cualquier atribución tal está siempre a expensas de ulterior información. En definitiva, la racionalización que el intérprete haga de las proferencias de los hablantes tiene todo el carácter de una hipótesis empírica susceptible de ser confirmada o de ser definitivamente falsada. El Principio de Caridad no es en absoluto incompatible con las exigencias de la investigación científica”"22 (el subrayado es mío)

\footnotetext{
lingüístico...” [la traducción es mía, en el original “...nothing could count as evidence that some form of activity could not be interpreted in our language that was not at the same time evidence that that form of activity was not speech behaviour...”]. Cfr. OVICS, p. 185.

${ }^{21}$ En realidad la teoría de Davidson se completa con dos principios más: el principio de autonomía semántica y el principio del triangulo. Cfr. Acero, J.J., Bustos, E., Quesada, D. Introducción a la filosofía del lenguaje. (Madrid: Cátedra, Colección Teorema, 1989) pp. 235-239. No es necesario a los fines de este trabajo hacer referencia a ellos. Sí en cambio cabe aclarar, para evitar confusiones, que no existe relación entre la noción de autonomía semántica davidsoniana y la que tiene en mente Schauer en ob. Cit. pp. 53-62 de la versión inglesa, pp. 113-122.
}

${ }^{22}$ Acero, Bustos, Quesada, ob. cit. p. 236. 
De lo dicho se sigue que si bien es cierto que se deben atribuir razones de un cierto tipo a la persona que expresa sus deseos en un lenguaje, esas razones no tienen porqué ir (aunque de hecho puedan ir) más allá de lo mínimo necesario para comprender en qué aspecto este individuo pretende que cambie el mundo. Se parte del presupuesto que el hablante cuando dice lo que dice cree que es conveniente que el mundo se adapte a ese deseo, pero de ello no se sigue necesariamente que el individuo posea una concepción sobre cuáles son los hechos o razones subyacentes a sus deseos. Su deseo se explica en virtud de que atribuimos cierta intención pero de ello no se sigue que esa intención, a su vez, pueda ser racionalizada necesariamente en una concepción más amplia sobre qué considera valioso sobre el mundo o sobre el tráfico. No necesitamos más que presuponer, en orden a comenzar a interpretar su lenguaje, razones de tipo conceptuales que indican qué quiso decir lo que dijo y qué quiere que el mundo cambie exactamente con respecto al estado de cosas que ha expresado (para nuestro ejemplo, que nadie circule a más de $60 \mathrm{~km} . \mathrm{h}$ ).

Es por tanto una cuestión de hecho, innecesaria a la hora de comenzar una actividad interpretativa, si el hablante tiene más razones que las que expresa su profirencia interpretada bajo razones de tipo conceptual. Es cierto que de hecho el individuo puede concebir a su deseo como enmarcado en una teoría más amplia sobre el bienestar social, pero la existencia de esta concepción subyacente a sus deseos es una cuestión de hecho que no necesita presuponerse para poder iniciar la traducción de su lenguaje.

Es posible entonces que autores como Schauer y Atienza-Ruiz Manero consideren a la idea de razones o justificación subyacente como el conjunto de criterios o precompromisos epistemológicos que debemos presuponer para que sea posible comenzar a interpretar el lenguaje jurídico. Sin embargo, como se ha mostrado, las razones conceptuales que deben presuponerse para que sea lógica o teóricamente posible comenzar una traducción no incluyen el tipo de razones en las que están pensando estos autores. No incluyen necesariamente la existencia de valores o razones subyacentes. Es perfectamente posible iniciar la interpretación de un lenguaje presuponiendo sólo razones conceptuales sin presuponer lo que aquí querría llamar razones evaluativas (i.e. razones que incluyen una cierta concepción sobre qué estado de cosas constituiría un mundo valioso, bueno, bello o correcto). Y, lo que es más importante, es posible que el resultado o conclusión de la interpretación arroje un resultado desconcertante: que el hablante no tenía en mente nada más que su deseo de que el mundo cambie en ese y sólo en ese aspecto. Por tanto, la atribución de razones evaluativas no es ni lógicamente necesaria en el comienzo de una interpretación, ni empíricamente necesaria en el final de la investigación lingüística, i.e. puede ser el caso que al 
finalizar nuestro investigación dogmática, descubramos que el legislador no tenía en mente ninguna concepción del bien, o seguridad en el tráfico. Como puede verse, no existe espacio dentro el modelo de Schauer-Atienza-Ruiz Manero para una conclusión similar. Llamaré a este razonamiento inválido -según el cual si hay que atribuir razones entonces hay que atribuir razones evaluativas- el non-sequitur interpretativo.

\section{IV.b. Razones conceptuales y razones evaluativas en la descripción del derecho. La metodología de la teoría del derecho. El non-sequitur descriptivo}

Algunos autores han sostenido (en contra de lo que se ha dicho en la subsección precedente) que la teoría misma del derecho es imposible si no se intenta al menos dar cuenta de un aspecto central del derecho y de las reglas: su referencia a valores y principios sustantivos ${ }^{23}$. Este enfoque es algo diferente y más amplio que aquél que sostiene que debemos presuponer valores o razones subyacentes a la hora de interpretar. Mientras que el modelo de más arriba sostiene (incurriendo en el non-sequitur interpretativo) que se deben presuponer razones evaluativas como presupuesto epistemológico o interpretativo, este modelo sostiene, más bien, que de hecho el derecho es una cuestión de valores y principios sustanciales de tipo moral, agregando que la descripción de valores sólo puede hacerse a través de evaluaciones análogas a las descriptas. Así, en este caso, parece sumarse al presupuesto epistemológico de la sección anterior un presupuesto ontológico: aquél según el cual el derecho, como hecho práctico, consiste en razones justificantes regularmente independientes de las fuentes sociales (de su pedigree). Dworkin, por ejemplo, ha sostenido que el derecho en sí mismo es un concepto interpretativo, i.e., un concepto que no podemos entender a menos que entendamos el valor u objeto del derecho el cual, para el autor, consiste principalmente en la justificación del ejercicio del poder coercitivo por parte del estado ${ }^{24}$. No pretendo entrar en la discusión sobre los problemas de este enfoque. Una respuesta rápida a esta concepción (lo que la hace, a su vez, rápidamente contestable) puede darse sosteniendo que aunque admitiésemos que la tarea central de un teórico del derecho es dar cuenta del aspecto central del derecho y, aún admitiendo que el propósito central del derecho

\footnotetext{
${ }^{23}$ Paradigmáticamente Dworkin R. Law's Empire (Cambridge: Harvard University Press, 1986) y Finnis, J. Natural Law and Natural Rights (Oxford: Clarendon Press 1980).

${ }^{24}$ Cfr. Dworkin, Ronald, Law's Empire, ob. cit. p. 190: “...una concepción del derecho debe explicar cómo lo que se considera derecho provee una justificación para el ejercicio del poder coercitivo por parte del estado...” [la traducción es mía. En el original “...a conception of law must explain how what it takes to be law provides a general justification for the excercise of coercive power by the state...”]
} 
es tratar de proporcionar algún tipo de justificación, de ello no se sigue que quien describe el derecho deba enrolarse en argumentos de tipo evaluativos como desea Dworkin (aunque como se verá, esta respuesta puede ser objetable). En este sentido la debilidad del enfoque de Dworkin es doble ya que:

i) si asumimos que el objetivo central del derecho es justificar la coerción estatal de acuerdo a determinados valores (morales o evaluativos de cualquier tipo) de ello no se sigue que para describir esa actividad de justificación debamos nosotros los intérpretes, ingresar en actividades evaluativas ${ }^{25}$;

ii) no hay porqué asumir (y esta es la crítica principal que se le dirge a Dworkin) que todo derecho o todo sistema jurídico de hecho se proponga como fin fundamental justificar la forma en que se ejerce el control social ${ }^{26}$.

\footnotetext{
${ }^{25}$ Salvo que se presuponga que la descripción de valores sólo puede ser hecha mediante otros valores. Si, en cambio, lo que se quiere decir es que para describir un valor, se necesita comprender el valor o entender más o menos lo mismo que se entiende por dicho valor en la comunidad bajo análisis, entonces no existe ninguna contradicción en sostener, sin juicio de valor alguno, "ellos consideran a X bueno". Hart resume esta intuición sosteniendo que "una descripción puede todavía ser una descripción, incluso cuando lo que se describe consiste en una evaluación”. En realidad tras esta discusión se encuentra el problema de en qué medida es posible comprender e interpretar un conjunto de valores sin enrolarse para esa misma empresa en argumentos evaluativos. El problema radica en la posibilidad de describir una cierta actitud interna frente a hechos prácticos desde el punto de vista externo. En lo que se ha llamado el giro hermenéutico de la obra Hartiana, se intenta explorar la posibilidad de describir o explicar las prácticas de una comunidad sin necesidad de colapsar la descripción en la valoración. Hart considera que no existe ninguna contradicción entre el hecho de comprender una práctica desde el punto de vista externo y su descripción como si fuésemos participantes en esa práctica (i.e. como individuos que ven en ciertas reglas algo más que mera regularidad). Desde esta perspectiva un analista de una práctica puede asumir un punto de vista externo no-extremo o hermenéutico que posibilita describir el punto de vista interno de aquéllos que aceptan dicha práctica y ven en ella una razón para la acción. Como se verá más adelante, esta creencia Hartiana de que ciertas prácticas pueden ser descriptas sin utilizar términos evaluativos -contrariamente a lo que pretende un Dworkiniano o un Finisiano- está supeditada a la creencia que el derecho (o sus casos centrales) de hecho no recurren en todo caso a categorías evaluativas. Sobre el giro hermenéutico en Hart, cfr. MacCormick, Neil. H.L.A.Hart (Londres: Edward Arnold, 1981) pp. 37-40. Raz, por su parte, parece sostener que es posible describir a pesar de que para ello debamos enrolarnos en argumentos evaluativos. Cfr. Cfr. Raz, J. "Two Views of the Nature of the Theory of Law. A Partial Comparison” en Coleman, Jules (ed) Hart's Postscript. Essays on the Postscript to the Concept of Law (Oxford: Oxford University Press, 2001) p. 21.

${ }^{26}$ Lo que se le critica a Dworkin precisamente es que la caracterización que termina ofreciendo del derecho es de tipo provincial o local, es decir, que termina por reconstruir como características de todo derecho lo que en realidad serían (y esto todavía está en discusión) características propias del derecho norteamericano. Cfr. Raz, J. "Two Views of the Nature of the Theory of Law. A Partial Comparison” en Coleman, Jules (ed) Hart's Postscript. Essays on the Postscript to the Concept of Law (Oxford: Oxford University Press, 2001) pp. 27-28 y 35-37.
} 
No obstante, se ha sostenido en el último tiempo que el verdadero desafío a la teoría iuspositivista no es el presentado por Dworkin, sino en realidad el propuesto por Finnis ${ }^{27}$. Una de las razones que justifica esta afirmación radica en que es posible afirmar que Finnis ha aceptado un aspecto metodológico central del giro hermenéutico hartiano, i.e.: ha concedido que dar cuenta de un fenómeno como el derecho sólo puede llevarse a cabo comprendiendo lo que los participantes ven (punto de vista interno) en las reglas. En este sentido, Finnis ha sostenido que:

“...las acciones, prácticas, etc., sólo pueden ser entendidas mediante la comprensión de sus cometidos centrales, es decir, entendiendo sus objetivos, sus valores, su significado e importancia en la misma forma en que es concebida por las personas que los tienen en cuenta y adhieren a ellos....28

Para Leiter esto es precisamente lo que acerca (en términos metodológicos) a Hart y Finnis, y pone a este último en una posición de prioridad con respecto a Dworkin en la contienda por el título de "anti-iuspositivista más importante”. En este sentido Leiter sostiene:

“...la última observación, sin embargo, no implica una disputa entre la teoría descriptiva de Hart, ya que Hart mismo acepta la restricción hermenéutica propia de las descripciones de los fenómenos sociales, es decir, aquélla según la cual una descripción adecuada de una práctica humana y social debe hacerse cargo de cómo los participantes en la práctica entienden su significado y propósito..." ${ }^{29}$

${ }^{27}$ Cfr. Leiter, Brian. "Beyond the Hart/Dworkin Debate: The Methodology Problem in Jurisprudence” en American Journal of Jurisprudence, 48, 2003, pp. 17-51. Aunque estoy de acuerdo con parte de los postulados de Leiter, considero algo exagerado sostener que el verdadero desafio al iuspositivismo lo constituye el iusnaturalismo. Es posible mostrar, cosa que no haré aquí, que iuspositivistas clásicos como Kelsen comparten con iusnaturalistas ciertos aspectos metodológicos (los cuales unos imputan a la racionalidad y otros a la naturaleza). En todo caso habría que distiguir entre dos tipos de desafíos al iuspositivismo: uno interno al discurso anglosajón (en donde Finnis sí representaría el máximo interlocutor del iuspositivismo) y uno externo que es representado por la Escuela Crítica que dirige sus ataques tanto a las reconstrucciones iusnaturalistas como a las iuspositivistas. No entraré en esta discusión aquí. Al respecto puede verse Ruiz, A.E.C, "Derecho, Democracia y teorías críticas al fin del siglo" en en Courtis, C. (comp.) Desde otra mirada. Textos de teoría crítica del derecho (Buenos Aires: Eudeba, 2001) pp. 10 y 11 y más en general Cárcova, C. "Iusnaturalismo y positivismo jurídico: un debate superado”, en Derecho, Política y Magistratura, Biblos, Buenos Aires, 1996.

${ }^{28}$ [la traducción es mía, en el original “...the actions, practices, etc., can be fully understood only by understanding their point, that is to say their objective, their value, their significance or importance, as conceived by the people who performed them, engaged in them, etc.”]. Cfr. Finnis, J. ob. cit. p. 3.

${ }^{29}$ [la traducción es mía, en el original “...the latter observation, however, states no dispute with Hart's descriptive Jurisprudence, since Hart too accepts the hermeneutic constraint on accounts of social phenomena: to wit, that an adequate description of a human social practice must attend to how the participants in the practice understand its meaning and purpose..."] Cfr. Leiter, B. ob. cit. p. 33. 
En consecuencia, sostiene Leiter, la auténtica disputa entre Hart y Finnis consiste en que el último afirma que si la preocupación teórica radica en dar cuenta de los casos centrales del derecho, y estos hacen referencia a cuestiones evaluativas basadas sobre las nociones de importancia, relevancia y razonabilidad práctica [practical reasonableness], entonces se debe echar mano a esas categorías al momento de describir. Un teórico del derecho debe, dice Finnis, considerar no sólo la existencia del derecho sino dar cuenta (cosa que no haría Hart) de por qué es valioso o relevante para una comunidad el poseer eso que poseen, esto es: el derecho ${ }^{30}$. Para Leiter, esto constituye en Finnis un non-sequitur con respecto a las premisas teóricas de partida (punto de vista interno, concepción hermenéutica, etc.). Veamos ahora cuáles son para Leiter las premisas a partir de las cuales Finnis incurre en este non-sequitur.

Según Leiter, Finnis injustificadamente ha concluido, desde puntos de partida epistemológicos-hermenéuticos, que se debe dar cuenta del valor, importancia y racionalidad práctica del derecho utilizando esos mismos valores. La crítica al non-sequitur tendría el siguiente contenido: del hecho que hayamos asumido que hay que entender qué tipo de razones ven este conjunto de juristas en el derecho, no se sigue que esas razones sean las que tiene en mente Finnis, ni que haya que hacerlo de la forma que piensa Finnis. Es posible describir los compromisos prácticos (hacia el derecho) que detenta un grupo, pero de ello no se sigue necesariamente que ese grupo tenga o desarrolle compromisos prácticos hacia el derecho basados en valores, importancia o razonabilidad práctica. Y, lo que sería más grave para Finnis, de ello no se sigue que en la selección y análisis de esos hechos sea el mismo teórico quien deba desarrollar valoraciones o evaluaciones teniendo en cuenta esos elementos. Aunque sea cierto que en el grupo analizado las evaluaciones proliferan (y este es todavía un debate abierto), no es cierto que para la selección y descripción de esas evaluaciones tengamos tambien nosotros como teóricos que entender el derecho a través de esas categorías. En definitiva, Leiter está sosteniendo que, aún cuando se asuma que el grupo posee ciertas categorías evaluativas para reconocer y seguir el derecho, de ello no se sigue que el teórico no pueda describir esas categorías (mencionarlas) sin usarlas. Por tanto:

i) está en disputa que los compromisos prácticos del grupo analizado consistan en ver en el derecho ciertas propiedades evaluativas o morales,

\footnotetext{
${ }^{30}$ Dice Finnis “...In relation to law, the most important things for the theorist to know and describe are the things which in the judgement of the theorist, make important from a practical viewpoint to have law...”. Cfr. Finnis, J. ob. cit. p. 16.
} 
ii) concediendo “i”, ello no nos fuerza a aceptar que el teórico deba utilizar esas mismas categorías para el análisis del objeto (el derecho);

Según Leiter la genealogía de este non-sequitur puede reconducirse a parte de los postulados post-Quineanos y post-Kuhnianos según los cuales no es posible describir ciertos hechos sin carga teórica alguna. El legado de Quine y Kuhn (erróneamente utilizado por Finnis) sostendría que es imposible describir un cierto hecho sin hacerlo, al mismo tiempo, con cierta carga teórica. Según Quine y Kuhn, en resumidas cuentas, no existiría descripción sin valoración y, por tanto, no existe ningún enunciado que pueda reclamar los créditos de objetividad o imparcialidad frente a los hechos. Esto equivale a poner en crisis el viejo ideal de eine wertfreie Wissenschaft (Weber). Nuestros enunciados teóricos, recuerdan estos autores, son estructuralmente teórico-dependientes [theory-ladden]. Leiter, sin contestar a este postulado, se limita a sostener que teóricos como Finnis han banalizado este presupuesto teórico, creyendo ver en él la confirmación de que la descripción de hechos prácticos (que ya Finnis asume con cierto contenido evaluativo) no puede hacerse sin utilizar de una u otra manera las mismas categorías que utiliza el grupo analizado. En fin, que describir prácticas evaluativas (como el derecho) no puede ser hecho sin cierta intoxicación. Finnis estaría afirmando que si el derecho consiste en valores, y queremos dar cuenta de esos valores, entonces debemos no sólo mencionarlos (como afirmaría un Hartiano) sino también usarlos.

En palabras de Leiter:

“...en la formulación de Finnis el non-sequitur tiene lugar...como resultado de lo que llamaré 'la Verdad o Afirmación Banal' según la cual '..las evaluaciones...constituyen un componente indispensable y decisivo en la selección o formación de cualesquiera conceptos a ser utilizados en la descripción de los aspectos de las cuestiones humanas tales como el derecho o el orden jurídico...' del cual se seguiría la afirmación de que la evaluación en cuestión implica '...decidir cuáles son las exigencias de razonabilidad práctica [practical reasonableness] que realmente existen...'. Yo considero como la 'Verdad o Afirmación Banal' el legado innegable de la filosofía de la ciencia post-Kuhniana y post-Quineana según el cual no existe tal cosa como la investigación carente de presuposiciones, o a partir de hechos que estén privados de 'carga teórica'. Pero eso está bastante lejos de la afirmación según la cual las presuposiciones propias de la empresa descriptiva requieren juicios o enunciados del tipo que Finnis llama ' razonabilidad práctica' ...o que el punto de vista desde el cual esos enunciados sobre la 'importancia' o 'relevancia' son hechos corresponda necesariamente a un 'punto de vista práctico'...”31

\footnotetext{
${ }^{31}$ [ la traducción es mía, en el original “... In Finnis’s formulation, the non-sequitur occurs in the slide from what I will refer to as the "Banal Truth" that "evaluations... are an indispensable and decisive component in the selection or formation of any concepts for use in description
} 
El núcleo básico de la crítica de Leiter a Finnis puede resumirse utilizando precisamente la expresión acuñada por las visiones de Quine y Kuhn. Ellos sostienen, en lo que se considera un topos en Filosofía de la ciencia y del lenguaje, que todo análisis de los hechos es irremediablemente theoryladen (teórico-dependiente). Leiter estaría sosteniendo que del hecho que nuestros análisis sean theory-laden, no se sigue que sean también morallyladen. Llamaré al non-sequitur atribuído por Leiter a Finnis, el non-sequitur descriptivo. El non-sequitur descriptivo tendría la siguiente estructura:

i) asume que la empresa teórica de descripción del derecho debe partir de un punto de vista hermenéutico;

ii) sostiene que las descripciones no están privadas de valoración o carga teórica [theory-free];

iii) dado que las descripciones son teórico-dependientes [theory-laden], por tanto son evaluativamente dependientes [morally-laden].

Sin embargo, en los párrafos que siguen me gustaría sostener que: aunque es innegable que Finnis asume el punto de vista hermenéutico; y es consciente del problema de la carga teórica o valorativa de los enunciados descriptivos, no es en virtud de ello que concluye que debe darse cuenta del derecho a través de esos valores. En definitiva, que aunque puede ser cierto que Finnis asume i-ii, no es cierto que, como cree Leiter, por ello concluye iii. Es más, trataré de poner en duda que la conclusión de Finnis sea precisamente la que quiere extraer Leiter del análisis de su trabajo. Simplemente trataré de mostrar que no surge tan claro del texto y párrafo citados que Finnis esté afirmando lo que Leiter pretende, i.e., que dado que nuestros juicios son teórico-dependientes [theory laden] por ello son moral o evaluativamente-dependientes [morally-laden]. Mi estrategia será mostrar que Finnis concuerda con Hart en "i" y disiente sobre el resultado de dicho punto de partida. Esto es, sobre el tipo de hechos que se verifican o constatan en el derecho (el contenido de las sentencias, la actitud de los participantes hacia las reglas, etc.).

Como se ha dicho previamente, existe un punto de convergencia entre la teoría de Hart y la de Finnis: ambos autores estarían de acuerdo en cuanto a las bases epistemológicas a partir de las cuales puede realizarse

of such aspects of human affairs as law or legal order" to the claim that the evaluation in question involves "decid[ing] what the requirements of practical reasonableness really are." I take the Banal Truth to be the uncontested legacy of post-Kuhnian and post-Quinean philosophy of science: there is no such thing as a presuppositionless inquiry, of facts that are 'theory-free,' and so on. But that goes no distance at all to establishing that the presuppositions of the descriptive enterprise require judgments about what Finnis calls "practical reasonableness" or that the viewpoint from which 'importance' and 'significance' are assessed is the 'practical view point'...”] Cfr. Leiter, B. op. cit. p. 34. 
una investigación en el terreno social (i). El punto de partida hermenéutico precisamente sostiene (como respuesta, p.ej. a los desafíos realistas) que si se quiere dar cuenta de la dimensión social de las reglas es necesario no sólo describir su seguimiento como mera regularidad, sino también dar cuenta de lo que los seguidores de reglas ven en ellas. Para Hart, paradigmáticamente, los participantes de una práctica observan a la regla como una razón para adecuarse a lo que ella impone y para criticar su desvío o violación. Aceptan a ella como razón para guiar sus conductas y para criticar la de los demás. Sin dar cuenta de este punto de vista interno hacia las reglas, un análisis del derecho se perdería de toda una dimensión explicativa del derecho como fenómeno social, debiendo reducirse a la mera constatación estadística de la regularidad y a la previsión de las reacciones futuras de los participantes. Hasta aquí el consenso entre Hart y Finnis. Sin embargo, gran parte de las críticas que se le han dirigido a Hart consisten en sostener que éste no ha tomado partido por el contenido de esas razones. Se sostiene que existirían buenos motivos para pensar que lo que los participantes ven como razón es en realidad una razón basada en valores morales. Por tanto, se sostiene, reconstruir el seguimiento de las reglas jurídicas en términos de razones es una condición necesaria para una descripción completa del fenómeno social del derecho, pero no suficiente. Se necesita, además, dar cuenta del contenido de esas razones que los participantes aceptan el cual no podría ser otro, se concluye, que moral o evaluativo. Hart, en respuesta a esto, ha sostenido claramente que el hecho que los individuos tomen a una regla como razón para la acción, la acepten y estén dispuestos a criticar su desobedencia, no implica necesariamente que dicho contenido sea de tipo moral. Es perfectamente posible, sostiene Hart, aceptar una regla por los más diversos motivos, los cuales no pueden reducirse (so pena de arbitrariedad) a meros motivos o razones morales. El derecho y sus reglas, sostiene Hart, pueden ser aceptados por las razones más diversas: como el oportunismo, cálculo, inercia, etc. ${ }^{32}$. Finnis, en cambio, está convencido de que los participantes conciben a las reglas jurídicas como algo inextricablemente ligado a la evaluación y a los valores morales. Mientras que Hart sostiene que la aceptación y contenido de las reglas no necesariamente incluye (en las sociedades modernas) contenidos de tipo moral, Finnis sostiene que observando las mismas prácticas a las que hace alusión Hart, pueden obtenerse conclusiones diversas. En este sentido puede sostenerse que Hart y Finnis concuerdan sobre la metodología (“i”) pero disienten sobre los hechos: mientras que uno cree haber constatado que de hecho existen reglas no basadas o no aceptadas por razones

\footnotetext{
${ }^{32}$ Cfr. H.L.Hart, The Concept of Law (1961), ed. por S. Bullock y J. Raz (Oxford: Clarendon 1994), p. 203.
} 
morales, el otro cree que todas las reglas son seguidas en base a razones morales y aceptadas en virtud de cuestiones evaluativas (al menos en los casos centrales del derecho). Como puede verse de esta reconstrucción, el disenso entre Finnis y Hart parece ser de tipo empírico o fáctico. Ambos concuerdan sobre las precauciones que habría que tomar para analizar un fenómeno social (enfoque hermenéutico) pero no concuerdan en los resultados que arroja la investigación, una vez tomadas esas precauciones. No resulta para nada claro cómo podría zanjarse una disputa de este género, i.e. sobre cuáles son los hechos que realmente existen en nuestras prácticas jurídicas (si aquéllos que toman a la regla como una razón sin tener en cuenta razones evaluativas o morales, o aquéllos que toman a la regla como una razón conectada con consideraciones morales). En todo caso está lejos de ser claro cuál sería el tribunal que debería decidir o mensurar el resultado de estas dos investigaciones, declarando el error de una y el acierto de la otra sobre los hechos prácticos $^{33}$. Una gran cantidad de casos judiciales muestran que los jueces siguen reglas sin tener en cuenta necesariamente razones de tipo moral (e identificando y aplicando el derecho de acuerdo al pedigree o su fuente social) mientras que otra gran cantidad no menos importante muestra que los jueces conciben al derecho como algo dependiente de fuentes sustanciales o morales. En todo caso parece claro que si Hart asumiese como resultado de su observación lo mismo que Finnis (i.e. que las actitudes hacia el derecho de los participantes incluyen aspectos evaluativos o morales) aceptaría la necesidad de dar cuenta del derecho en términos de valores y no de fuentes sociales. Si fuese cierto que todas las razones que ven los participantes en las reglas se reconducen a valores morales ello forzaría de una manera u otra a dar cuenta de ello de una forma análoga a como dan cuenta los participantes, i.e. mediante juicios y enunciados de valor. Si dar cuenta de lo que ellos ven en el derecho supone al menos dar cuenta de eso en los mismos términos en que lo hace el grupo analizado (so pena de pérdida del poder explicativo de nuestra teoría), parece forzosa la conclusión de que en el caso de que le asista razón a Finnis, sólo podría describirse el derecho utilizando al menos categorías y enunciados análogos a los que tienen en cuenta el grupo bajo análisis, i.e. mediante la utilización de términos conectados o relacionados con la valoración moral ${ }^{34}$.

\footnotetext{
${ }^{33}$ Con tribunal me refiero aquí expresamente a la expresión acuñada por Quine según la cual se plantea la posibilidad y conveniencia de reconducir nuestras disputas al tribunal de la experiencia (método empírico) o a otro diverso (como querría un racionalista o iusnaturalista).

${ }^{34}$ Hart podría redoblar la apuesta, sosteniendo que ello tampoco nos compromete con utilizar términos evaluativos o morales a la hora de describir las prácticas (que ya hemos asumido como valorativas o conectadas con la moral). Si esa fuese la respuesta, ello acarrearía un
} 
Es posible entonces reconstruir la divergencia entre Hart y Finnis como un acuerdo sobre la metodología y un desacuerdo sobre los hechos que se obtienen u observan a partir de aquélla. Si esto es así, entonces es falso que Finnis haya incurrido en el non-sequitur descriptivo que le atribuye Leiter. En efecto, bajo la perspectiva que aquí se propone, Finnis no está diciendo que dado que nuestras descripciones son teórico-dependientes (intoxicadas por las valoraciones, theory-laden) entonces son valorativamente-dependientes [morally-laden]. La conclusión de que en efecto los participantes conciben al derecho y a las reglas como una práctica basada en valores sustanciales y no en fuentes sociales no se sigue de los puntos de partida epistemológicos o metodológicos de Finnis (de ser así incurriría en el nonsequitur descriptivo) sino de los hechos que él cree observar una vez que ha realizado su investigación social con ciertas precauciones. Finnis cree haber constatado una propiedad persistente en el derecho según la cual concebimos al derecho como una práctica relacionada con valores sustanciales y que privar al análisis del derecho de este componente nos dejaría sin posibilidad de describir el aspecto central del fenómeno. Sostiene, en definitiva, que el derecho es una cuestión de valores una vez que hemos realizado nuestra investigación con ciertas precauciones metodológicas y no porque la hemos realizado con esas precauciones. No existe non-sequitur alguno en sostener que en la investigación se adopta un punto de partida hermenéutico y que el resultado de la investigación arroja como hechos sociales un conjunto de fenómenos conectados con la moral. Es cierto, sin embargo, que Finnis termina sosteniendo que los enunciados teóricos son dependientes de evaluaciones morales [morally laden] pero sostiene ello como resultado de la conjunción entre los puntos de partida metodológicos y el resultado que la observación de las prácticas ha arrojado, y no sólo, como pretende Leiter, como consecuencia de los primeros. Por tanto Finnis sostendría:

i) que la empresa teórica de descripción del derecho debe partir de un punto de vista hermenéutico;

ii) que el derecho es una cuestión de valores morales o de actitudes morales hacia el derecho;

efecto dominó precisamente sobre su punto de partida herméutico porque estaría afirmando que podemos dar cuenta de un punto de vista interno (en este caso eminentemente moral o valorativo) en términos completamente extraños al lenguaje en que son formulados y reconocidos dichos valores. Estaría en definitiva, abandonando la idea según la cual una explicación es mejor que otra si acerca lo más posible a los términos en que la comunidad analizada concibe un fenómeno. Parece existir una cierta contradicción en sostener que estamos comprometidos en describir y dar cuenta de los fenómenos sociales de un grupo de acuerdo a como ellos los conciben y el sostener, a su vez, que podemos hacer ello en términos completamente extraños a la terminología y concepción analizada. 
iii) que las descripciones no están privadas de valoración o carga teórica [theory-free];

iv) que dado que "i” y “ii” son verdaderas, no puede realizarse un análisis del derecho, sin que ello implique necesariamente asumir en el análisis el tipo de valoraciones que se tienen en cuenta en el fenómeno analizado;

Es precisamente “ii” el punto de disenso entre Hart y Finnis. Es sólo porque Finnis asume la conjunción entre un punto de partida epistemológico y cierto resultado de la investigación realizado a partir de ellos, que afirma que los hechos existentes deben describirse realizando al menos las mismas asunciones y valoraciones que se llevan a cabo en el lenguaje objeto. Dado que Hart no asume“ii” como propiedad necesaria de todos los sistemas jurídicos, puede concluir que no es necesario realizar valoraciones del tipo que tiene en mente Finnis. Para Hart, y no para Finnis, todo lo que arroja nuestra investigación sociológica sobre los sistemas jurídicos modernos es cierta estructura conceptual que permanece (unión de reglas primarias y secundarias, reglas como razones, etc.) y un conjunto de propiedades que no permanecen (recurso a la moral, contenido evaluativo de las razones etc.). En términos de Raz:

“...una característica central de la explicación de Hart acerca de la naturaleza del derecho se refiere a que este, en última instancia, es absolutamente independiente de su contenido [sustancial]. Es decir, que los criterios fundamentales para decidir la validez, aquéllos cuya existencia no presupone a su vez otros, son completamente y en última instancia independientes de su contenido. La teoría del derecho sostiene que los sistemas jurídicos son sistemas con cierta estructura (que incluye autoridades de producción y aplicación de leyes). Pero, más allá de ello, todo lo demás es contingente. El contenido del derecho y la específica identidad y poder de sus instituciones es completamente dependiente de la prácticas de cada país, esto es, de su regla de reconocimiento...”35

Para Finnis, en cambio permanece no sólo la estructura conceptual remarcada por Hart sino otra más importante: el recurso a valores o evaluaciones morales.

\footnotetext{
35 [la traducción es mía, en el original: “....a central feature of Hart’s explanation of the nature of law is that it is just about absolutely content-independent at bottom. That is, the fundamental criteria for validity, those whose existence does not presuppose others, are almost entirely content-independent at bottom. Jurisprudence stipulates that legal systems are systems with a certain structure (including law-making and law-applying authorities). But beyond that, all is contingent. The content of the law and the specific identity and powers of its institutions are entirely dependent on the relevant practices in the country, i.e. on its rule of recognition.....”] Raz, Joseph. "Two Views of the Nature of the Theory of Law. A Partial Comparison" en Coleman, Jules (ed) Hart's Postscript. Essays on the Postscript to the Concept of Law (Oxford: Oxford University Press, 2001).
} 
En síntesis, aunque puede ser discutible la afirmación empírica o fáctica de Finnis, parece cierto que dicha afirmación no se debe a un non-sequitur como cree Leiter. Finnis sostiene que una vez analizados los hechos con cierta cautela, ellos muestran una cierta conexión lógica con ciertos valores. Y que dado que hemos asumido describir estos hechos sociales de la forma más cercana a como se realiza en la comunidad analizada, no queda otra salida que tratar de dar cuenta de esos valores utilizando en la medida de lo posible las nociones que los participantes usan. Hart en cambio, no cree que los participantes de todo sistema jurídico utilicen esas nociones con contenido sustancial. Por tanto puede mantenerse respetuoso al approach hermenéutico ("describe los hechos dando cuenta de la clase de cosas que ellos ven en esas prácticas”) formulando sus análisis en términos no evaluativos. Creo que es posible concluir que si Hart aceptara “ii” (coincidiera con Finnis sobre la naturaleza de los hechos prácticos analizados) se vería obligado por el approach hermenéutico a dar cuenta de esos hechos al menos en términos no absolutamente extraños a los términos en que se expresan y actúan los participantes, i.e. utilizando términos valorativos. Independientemente de esto, parece claro que Finnis no incurre en la banalización del legado postQuineano y post-Kuhniano como pretende Leiter. Finnis no sostiene que dado que nuestros enunciados son teórico-dependientes, entonces son evaluativo-dependientes. Más bien está diciendo que nuestros enunciados son teórico-dependientes y que deben utilizarse con cierta cautela metodológica. Y que una vez tomada en cuenta la debida cautela, su investigación arroja como resultado que los hechos así analizados tienen contenido moral o evaluativo. En síntesis, el non-sequitur descriptivo no sería atribuible a Finnis dado que él no sostiene que nuestras descripciones son moral o evaluativamente-dependientes porque son teórico-dependientes, sino más bien porque cree que de hecho el derecho consiste en valores. Su afirmación se reduce a sostener que nuestros enunciados descriptivos son evaluativamente-dependientes porque el derecho es evaluativamente-dependiente.

Una vez aclarada la diferencia entre estos dos non-sequitur me interesa volver a la noción de non-sequitur interpretativo tratando de mostrar que a través de ella se olvida la utilización de la guillotina de Hume y se impide la descripción de fenómenos sociales de manera adecuada.

\section{La falacia naturalista y la idealización de los procesos de decisión colectiva}

Uno de los aspectos más discutidos en Filosofia analítica -al menos hasta el segundo tercio del siglo XX- ha sido la posibilidad de derivar enunciados prescriptivos de enunciados descriptivos o, más simplemente, de derivar una obligación de una descripción [Ought from Is]. En base a postulados que 
encuentran sus raíces en Hume, se ha sostenido que existe un cierto salto o abismo lógico entre enunciados de estos dos tipos. La problemática y desafío que se genera a raíz de las afirmaciones de Hume ha sido denominada como el problema de la Guillotina de Hume ${ }^{36}$. Esta discusión se relaciona estrechamente con la posibilidad de construir a su vez una lógica de normas. Si la noción de consecuencia lógica está íntimamente ligada con la noción de verdad y falsedad de los enunciados contenidos en un razonamiento, y si es cierto que las normas no son verdaderas ni falsas, entonces parece cierto que no puede construirse una lógica de normas. Los problemas, entonces, se subdividen en dos grandes grupos ${ }^{37}$ :

i) ¿Es posible construir un puente entre enunciados descriptivos y prescriptivos, entre ser y deber ser? (discusión que ha tenido como principales protagonistas a Jørgensen, Black y Searle);

ii) ¿Son las normas verdaderas o falsas?.

La respuesta relativa al primer interrogante depende en gran medida de la respuesta (y postura) que se adopte con respecto al segundo. Existen dos tipos de respuestas con respecto a éste último. Aquélla que responde con un rotundo "no, las normas no son ni verdaderas ni falsas” y aquélla que responde afirmativamente. Esto a su vez divide el enfoque sobre las normas en dos grandes grupos: prescriptivismo (no cognitivismo) y descriptivismo (cognitivismo).

El prescriptivista sostiene que las normas no tienen valor de verdad y que su existencia depende de una proferencia o expresión de deseo o voluntad de una persona o grupo de personas (llámese a esta autoridad normativa, autoridad legislativa, etc.). Cuando una persona sostiene que existe una norma por la cual se debe hacer $A$ o bien expresa que ese es su deseo (caso de legislación autónoma, el individuo decide una norma a la cual someterse) o sostiene que ese es el deseo de un grupo de personas (caso de legislación heterónoma). En todo caso, sostener que existe una norma bajo esta concepción es sostener al menos un deseo y predisposición a ajustar la conducta al estado de cosas previsto en la norma y sólo eso. En términos del dilema del Eutifrón (Platón) algo no se quiere o desea porque es debido (bueno, valioso, etc.) sino que algo es debido (bueno o valioso, etc.) porque se desea. Es debido porque se desea, y no a la inversa. En este caso el aspecto decisivo o

\footnotetext{
${ }^{36}$ La expresión proviene de Max Black. “The Gap between 'Is' and 'Should'», Philosophical Review, 73 (1964).

${ }^{37}$ Sigo en este punto la presentación hecha por G.H.Von Wright en "Is and Ought” en Bulygin E., Gardies, J-L y Niiniluoto, I. (eds.) Man, Law and Modern Forms of Life (Boston: Kluwer Academic Publishers, 1985) pp. 263-281.
} 
volitivo (en el prescriptivismo) tiene una capacidad constitutiva de un deber. Se debe porque se desea ${ }^{38}$.

El cognitivismo, por su parte, afirma rotundamente la posibilidad de hablar de normas y valores en términos de verdad y falsedad. Para esta perspectiva, no habría ninguna dificultad en construir una lógica de normas standard utilizando la idea de consecuencia lógica. Asumir que las normas son verdaderas o falsas supone, por un lado, asumir un presupesto ontológico más fuerte que el que asume el prescriptivismo y, por el otro, borrar del mapa el problema del salto o abismo lógico entre la isla del ser y la del deber ser. El cognitivismo afirma, en resumidas cuentas, (y este es el caso del iusnaturalismo) que no se entiende muy bien porqué habría que construir un puente entre dos lugares ubicados en la misma tierra firme.

Independientemente de esta discusión (en la que no pretendo entrar en este trabajo), parece innegable que un iuspositivista coherente debería sin duda ubicarse en el campo no-cognitivista o prescriptivista de las normas y de allí sostener que aquéllo que parece un salto lógico es en realidad un producto de la decisión humana individual o grupal (v.g. del Poder Legislativo). La guillotina de Hume sirve precisamente para desenmascarar (si es que se asume que hay algo que desenmascarar) el paso de premisas descriptivas a prescriptivas encubierto bajo afirmaciones iusnaturalistas como “...existe, por tanto es bueno; es bueno, por tanto es debido...”. Lo que trata de mostrar un prescriptivista (y un iuspositivista en general) es que entre estas tres premisas existe al menos una decisión de un grupo de personas dirigida a lograr que el mundo cambie o se adapte en algún aspecto. Dicho más simplemente, que existe una decisión imputable a alguien y toca a nosotros ver quién la ha realizado, cuál es su contenido y en qué medida ella se encuentra justificada de acuerdo a otros valores (políticos, prudenciales, etc.). Por tanto el rendimiento de esta categoría radica precisamente en que reduce la existencia de obligaciones jurídicas a la decisión de sujetos y, como consecuencia, no reconstruye a esos deberes como imputables a cómo es el mundo o a cómo es la naturaleza. La actividad del científico del derecho en este caso consiste en detectar cuándo se ha decidido que un cierto estado de cosas tenga lugar (se ha dictado una norma), cuál es su contenido y porqué esa decisión puede ser plausible, razonable o criticable. Parece claro que esto no puede ser hecho sino se detecta cierto problema en el paso de

\footnotetext{
${ }^{38}$ En términos de Von Wright “el asentir (o aceptar) una norma no es afirmar su verdad -y el no asentirla (o no aceptarla) no implica negar su verdad. Aseverar o rechazar una norma se parece más a un acto de legislación o de otorgamiento de una norma a uno mismo" [la traducción es mía, en el original “...to assent a norm is not to affirm a truth -and to dissent is not denial (of truth). To assent (or dissent) is more like an act of legislation or norm-giving itself....”, ob. cit. p. 278.
} 
premisas descriptivas a prescriptivas y no se asume que hay alguien que ha decidido que el mundo debe ser así. El prescriptivismo, el iuspositivismo en general, de la mano de la guillotina de Hume pretende sostener:

i) por un lado que no existen deberes per se, o naturales;

ii) por el otro, que es necesario aceptar un salto lógico entre ser y deber ser si queremos encontrarnos en condiciones de detectar dónde se ha cometido el salto y quién lo ha llevado a cabo ${ }^{39}$;

iii) y, por “ii”, que el contenido y alcance de esos deberes depende del contenido y alcance de la decisión humana, esto es, de la efectiva forma en que esos sujetos han decidido ordenar el mundo y qué cosas han tenido en cuenta al formular una norma;

Enfoques como los de Schauer-Atienza-Ruiz Manero mezclan injustificadamente estas máximas iuspositivistas con ciertas nociones iusnaturalistas y asumen que las decisiones humanas (las normas promulgadas) tienen necesariamente un cierto contenido (razones subyacentes o base justificante) lo cual, como se mostró más arriba, constituye un non-sequitur interpretativo. Si asumimos que los deberes son un producto humano (fuentes sociales) y que, por tanto, el contenido de ese deber creado depende de lo que ese grupo humano realmente tenía en mente al momento de dictarlo (y no aquéllo que idealmente deberían tener en cuenta al momento de legislar) se puede concluir que no es cierto que siempre tras el dictado de una norma (tras la decisión prescriptivista) existan razones subyacentes (entendidas en sentido evaluativo). La guillotina de Hume en conjunción con el prescriptivismo muestra que los deberes tienen el contenido que tienen dependiendo de lo que quiso o no el grupo de sujetos que los promulga y no el contenido que deberían tener de acuerdo a otro sistemas de valores. En todo caso, que la adecuación entre los deberes existentes (dictados por la autoridad) y cierto sistema de valores es un aspecto contingente. No sólo puede ser cierto que

${ }^{39}$ En realidad la tesis de, p. ej. Von Wright, trata de mostrar que no habría tal cosa como un salto porque el deber en cuestión no nace de los hechos, sino de cierta decisión normativa. En todo caso lo que Von Wright estaría asumiendo es que o bien asumimos que el puente entre ser y deber es insalvable, o bien asumimos que no estamos saltando de un punto hacia el otro, sino que siempre nos hemos movido en el terreno de los deberes y las consecuencias que se siguen de ellos. En este sentido me aventuro a decir que la estrategia de Von Wright es precisamente la negación de la estrategia naturalista. Esta dice que no hay necesidad de un puente porque todos los aspectos se encuentran en el mismo ámbito del ser, mientras que Von Wright estaría sosteniendo que no hay necesidad de un puente, porque seguimos hablando (si somos prescriptivistas) de deberes y las consecuencias que se siguen de ellos. Agrega, en esta línea, que la sensación de este salto viene dada por una confusón de planos entre lo que la norma prescribe y el estado de cosas que debería existir en el mundo para que esa norma fuese satisfecha (diferencia entre deber "normativo" y deber "técnico" relativo a la relación entre medios y fines). Cfr. ob. cit. pp. 276 y 277. 
el poder legislativo tenga en cuenta una base axiológica distinta a la que poseemos nosotros (caso de discordancia entre dos esquemas axiológicos) sino que puede ser también cierto que la autoridad no tenga en cuenta ninguno. Asumir que el legislador en cada promulgación de una norma tiene en cuenta al menos una base axiológica o justificante a partir de la cual decide lo que decide es precisamente asumir lo que un iuspositivista debería negar. Siempre y cuando se pretenda conservar la posibilidad de distinguir entre lo que el derecho de hecho es, y lo que debería ser. Un iuspositivista traiciona sus puntos de partida metodológicos no sólo cuando colapsa el sistema axiológico utilizado por el legislador en su propio sistema de valores, sino también cuando asume que sea cual sea el caso, el legislador siempre tiene al menos un sistema de valores que pretende favorecer o desalentar.

A su vez, la conjunción de estas herramientas metodológicas (diferenciación entre hecho y valor, inderivabilidad del ser del deber ser, guillotina de Hume, normas como producto de decisiones humanas, prescriptivismo, etc.) no sólo constituye una herramienta de análisis fundamental para quien, como el iuspositivista, decide limitarse a describir los aspectos estructurales o conceptuales de un sistema jurídico, sino también para quien decide describirlos y someterlos a crítica (apelando a la historia, la economía, la sociología, la política, etc. $)^{40}$. Es precisamente la vertiente Crítica quien ha insistido en la necesidad de desmitificar los procesos de legislación y decisión colectiva, invitando a deconstruir los verdaderos factores que motivan una decisión legislativa (ideológicos, económicos, políticos). No hay porqué pensar que el proceso de legislación se reduzca necesariamente (aunque sería bueno que lo hiciese) a promulgar normas teniendo en cuenta el mejor estado de cosas posible para una determinada comunidad. Más bien, los datos que provienen de la sociología y la historia muestran que en la decisión legislativa intervienen aspectos de los cuales el legislador puede ser completamente consciente

\footnotetext{
${ }^{40}$ Es posible sostener que críticos y iuspositivistas discrepan precisamente sobre cuáles son los hechos de los que debería dar cuenta una teoría para considerarse completa o satisfactoria. Hasta donde alcanzo a ver la teoría Crítica en general (y la Argentina en particular) no sostiene que los análisis positivistas (basados en la lógica y la filosofía del lenguaje) sean falsos, sino que son reduccionistas y por tanto insuficientes. En este sentido la escuela Crítica no objeta la incorrección de esas herramientas sino la idea que el análisis del derecho pueda reducirse a esos y sólo a esos aspectos. En este sentido, p. ej., Cárcova afirma “....sin embargo, los positivistas vernáculos suelen incurrir en este respecto en equívocos teóricos y excesos retóricos...., es el carácter reductivo y por lo tanto insuficiente de esa concepción, que sólo considera la dimensión normativa del fenómeno jurídico, dejando ‘afuera', esto es, declarando impertinentes, sus dimensiones éticas, políticas, teleológicas, etc., lo que facilita la aureola de sistematicidad de que es portadora...” (el subrayado es mío) Cfr. Cárcova, C.M. "Notas acerca de la Teoría Crítica del Derecho” en Courtis, C. (comp.) Desde otra mirada. Textos de teoría crítica del derecho (Buenos Aires: Eudeba, 2001) p. 20.
} 
(favorecimiento de un grupo mayoritario en detrimento de las minorías, favorecimiento de un interés de clase en detrimento de las mayorías, etc.) o completamente inconsciente de la base justificante de sus actos (actuando como vehículo inconsciente de poder, para utilizar una frase acuñada por Foucault, i.e. con desconocimiento de cuáles son los valores políticos o morales que está favoreciendo).

En todo caso, la existencia tras la regla de una concepción de cómo debería ser el mundo o qué cosa maximizaría el bienestar de un grupo es un aspecto contingente, que dependerá de la calidad y legitimación de cada órgano legislativo en particular. No es para nada obvio que las normas emanadas de la legislatura posean siempre esa carga de racionalidad que le pretenden atribuir enfoques como los que incurren en el non-sequitur interpretativo. En todo caso sería valioso que el legislador fuese racional (y aún resta decidir bajo qué condiciones diríamos que alguien es racional) pero de ello no se sigue que de hecho lo sea. Y tampoco se sigue que sea necesario, en el plano interpretativo, atribuir más que una modesta carga de racionalidad basada en lo que aquí se ha llamado razones conceptuales.

\section{Conclusiones}

i) Es falso que para interpretar un lenguaje jurídico deba presuponerse más cosas que lo que aquí se ha llamado razones conceptuales. El montaje teórico de autores como Davidson invita a atribuir sólo este tipo de razones y deja abierta la posibilidad de que la investigación empírica demuestre (contingentemente) que existen lo que aquí se ha llamado razones evaluativas;

ii) La confusión entre razones conceptuales y razones evaluativas puede ser vista como una revitalización del legislador racional, i.e. la creencia según la cual el legislador siempre tiene en cuenta las circunstancias a las cuáles se aplica la regla y formula en base a ello un balance de razones que se concreta en el dictado de una regla con razones subyacentes;

iii) Es posible trazar una distinción entre lo que aquí se ha llamado nonsequitur interpretativo y el non-sequitur descriptivo. Uno atribuye razones evaluativas como presupuesto o precompromiso de interpretación, el otro atribuye razones evaluativas en base a la creencia (heredada de Quine y Kuhn) según la cual no existen enunciados descriptivos puros (Leiter);

iv) El non-sequitur descriptivo no sería atribuible a Finnis dado que él no sostiene que nuestras descripciones son moral o evaluativamentedependientes porque son teórico-dependientes, sino más bien porque cree que de hecho el derecho consiste en valores. Su afirmación se 
reduce a sostener que nuestros enunciados descriptivos son evaluativamente-dependientes porque el derecho es evaluativamente-dependiente;

v) Reconstrucciones como la de Schauer-Atienza-Ruiz Manero contradicen abiertamente los puntos de partida iuspositivistas (prescriptivismo, tesis de las fuentes sociales, distinción entre ser y deber) dado que sostienen como necesarias características del derecho que son sólo contingentes;

vi) La distinción entre ser y deber ser y las precauciones metodológicas a las que invita la guillotina de Hume son tanto útiles para un iuspositivista como para quien pretende describir y luego someter a crítica el tipo de relaciones de poder que se suscitan y que explican los procesos de decisión colectivos;

No resulta para nada inusual que algunos teóricos mitifiquen ciertos aspectos del derecho. Esto alcanza por igual a iuspositivistas y iusnaturalistas. En todo caso, sigue siendo valioso esforzarse por mostrar cómo ciertas estrategias conceptuales y semánticas (como las del derecho entendido en función de razones) pueden tanto prestar un valioso servicio teórico como naturalizar una cierta forma de pensamiento. La naturalización de cierta forma de pensamiento es y será siempre un síntoma o indicio de cierta ideología que merece ser (al menos) revisada y, en el peor de los casos, desechada. El desafío continúa siendo, creo, tratar de detectar cuándo algo que se presenta como necesario es meramente contingente, y qué consecuencias se siguen de tal descubrimiento para la teoría, la política y la moral. 